\title{
MODELAGEM DOS IMPACTOS ECOLÓGICOS DO PROJETO HIDROVIÁRIO DA LAGOA MIRIM (BRASIL-URUGUAI), BASEADA EM RACIOCÍNIO QUALITATIVO
}

\author{
GOULART, F. F. ${ }^{1} \&$ SAITO, C. H. ${ }^{2^{*}}$ \\ 1 - Universidade de Brasília, Programa de Pós-Graduação em Ecologia \\ 2 - Universidade de Brasília, Dept. Ecologia e Programa de Pós-Graduação em Desenvolvimento \\ Sustentável \\ *Corresponding author: carlos.h.saito@hotmail.com
}

\begin{abstract}
Goulart, F. F. \& Saito, C. H. (2012) Modelling ecological impacts of the waterway of Mirim Lagoon (Brazil-Uruguay), based on Qualitative Reasoning. Braz. J. Aquat. Sci. Technol. 16(1):19-31. elSSN 1983-9057. This study is an application of the scientific mediation process through modeling the physical, chemical and biological impacts of a waterway construction in Mirim Lagoon. Qualitative modelling process, based on Qualitative Reasoning, was conduced to better understand the ecological impact on water environment. The qualitative reasoning simulation show clear trends towards a loss of the physiochemical natural characteristics of the lagoon ("backwater effect") and a decline of macrophyte, invertebrate, water birds and fish species. Furthermore, the simulation showed the spreading of the golden mussel (Limnoperma fortunei), which is an invasive species.
\end{abstract}

Key words: Mirim Lagoon, qualitative modeling, environmental impacts, waterway, Limnoperma fortunei, backwater effect

\section{INTRODUÇÃO}

A construção de hidrovias é um tema controverso tanto no âmbito político quanto no acadêmico propriamente dito. Por exemplo, instalou-se grande polêmica a respeito da construção da hidrovia Paraná-Paraguai uma vez que tal empreendimento foi considerado que viria a impactar profundamente a fauna do Pantanal, causando um prejuízo ecológico (Bucher \& Huszar, 1995; Gottgens et al., 2001) de imensas proporções com profundos impactos econômicos e culturais, sobretudo na atividade pesqueira e de turismo (Banducci, 2003). Por outro lado, suposto ganho econômico desses empreendimentos é questionável. Uma análise da viabilidade econômica mostrou que os custos ambientais podem exceder o lucro gerado (Buscher \& Ruszar, 1995; Cardoso et al., 2006). Mesmos estudos que apontam para uma viabilidade econômica reconhecem a alta competitividade econômica entre os modais, ferroviário, rodoviário e hidroviário (Gonçalves, 2008).

Um dos exemplos de impactos de hidrovias na biota é o caso de Everglades na Flórida. A quantidade de espécies de aves observadas é $5 \%$ do registrado antes do empreendimento (Brumbach, 1990). A dragagem diminuiu a quantidade de habitats para invertebrados bentônicos em $70 \%$ e a atividade de pesca declinou em $80 \%$ desde 1940. Apesar disso, o lucro das atividades econômicas decorrentes dos empreendimentos hidroviários pode ser compensado, ou até mesmo superado pelas perdas econômicas geradas a partir de enchentes como conseqüência do aumento da velocidade da água pela dragagem dos meandros. No caso dos EUA, só uma grande enchente em 1993 foi responsável por um prejuízo de 12 bilhões de dólares (Gottgens et al., 2001).

A Lagoa Mirim possui $3.750 \mathrm{~km}^{2}$, sendo que $82 \%$ da sua superfície encontram-se dentro do território brasileiro e $18 \%$ no Uruguai, constituindo a segunda maior massa hídrica com características lacustres do Brasil (Steinke, 2007). A região da Lagoa Mirim apresenta grande biodiversidade, e recebe importante afluxo de aves migratórias, sendo considerada área prioritária para conservação de invertebrados, mamíferos, aves, anfíbios e répteis (Menegheti, 2008a; MMA, 2000). Consequentemente, ela foi sugerida para tornar-se sítio Ramsar como uma região globalmente prioritária para a conservação de áreas úmidas (Kotzian \& Marques, 2004).

Apesar dessa ampla superfície, a lagoa possui baixa profundidade, o que levou a vários casos de naufrágio no passado (Meneghethi, 2008b). Mesmo diante dessa limitação física, a proposta de construção de uma hidrovia é uma demanda antiga da região, apesar de ser importante ressaltar que o contexto histórico é outro, e o vetor de pressão pela construção da hidrovia também é outro, diferindo significativamente em termos de magnitude dos interesses econômicos envolvidos. Em Saito e Steinke (2010), é analisado este novo momento, que vem sendo chamado de "nova identidade para o Pampa", "no qual a indústria de celulose chega com força econômica suficiente para suprimir as discussões no âmbito da conservação da biodiversidade, visto que busca ampliar sua área de plantio e conversão de celulose em papel no Brasil, Argentina e Uruguai, bem como influenciar a implanta- 
ção de infra-estrutura de processamento e transporte, sobretudo de navegação, na região" (p.219). Segundo Saito (2009), neste cenário, observa-se um processo de apropriação dos interesses históricos como álibi dos novos interesses. Tais propostas foram concretizadas a partir de dois projetos (Dêntice, 2007; Timonsur, 2003), submetidos aos governos uruguaio e brasileiro para construção de uma hidrovia em seus respectivos territórios, que resultam numa ação integrada.

Diante desse cenário, cabe destacar que compreender a cadeia de causalidade que envolve a instalação da hidrovia e desenvolver a capacidade de antever os impactos desta nos parâmetros físico-químicos e biológicos é importante para mediar o debate em torno da sua implantação ou não, e as alternativas de projeto. Essa mediação, portanto, deve promover a tradução dos fenômenos socioambientais em modelos envolvendo as relações causais tal que permita embasar uma maior compreensão do mundo pelos sujeitos, tornando-os mais participativos e conscientes do ambiente que os cerca. A superação das compreensões triviais e acrítica da realidade, pelo correto dimensionamento dos conflitos socioambientais, se reveste como ação de educação ambiental e alfabetização científico-tecnológica de fundamental importância para a inserção dos indivíduos nos processo de conhecimento e atuação sobre a realidade (Saito et al., 2008; Saito et al., 2011), assegurando um processo de empowerment e emancipação (Friedman, 1992).

No contexto da Lagoa Mirim, o presente trabaIho busca promover essa mediação científica de forma a auxiliar na compreensão da cadeia de causalidade que envolve a instalação da hidrovia. Assim, o objetivo deste trabalho é realizar uma modelagem qualitativa, baseada em Raciocínio Qualitativo, dos impactos físico-químicos e biológicos da instalação de uma hidrovia na Lagoa Mirim, RS.

\section{MATERIAIS E MÉTODOS}

Optou-se pela modelagem em Raciocínio Qualitativo (RQ) cuja abordagem tem sido amplamente utilizada na descrição de problemas ecológicos complexos (Salles \& Bredeweg, 1997; Salles et al., 2006; Araújo et al., 2008). O RQ é uma área da Inteligência Artificial voltada para a descrição de entidades, suas propriedades, e relacionamentos entre as mesmas, de forma a compreender a dinâmica processual das relações, ainda que não se disponha de dados numéricos precisos que permitam estabelecer uma fiel correspondência com a realidade (Forbus, 1984). É importante considerar que essa falta de dados confiáveis para séries temporais e espaciais, constitui um dos grandes entraves para a modelagem de ecossistemas aquáticos no Brasil (Angelini \& Gomes, 2008).

A abstração de valores, tal que a dinâmica processual possa ser reproduzida por meio de estados qualitativos, espaços quantitativos macro e magnitude de variação, constitui a meta dessa forma de modelagem qualitativa, e deve permitir a emergência dos conceitos e sua apreensão.

Basicamente, os conhecimentos apreendidos em modelos qualitativos são:

1) As entidades ou objetos, que por si, já representam conceitos. Quando objetos correspondem a fatores externos que interferem no sistema, estes são chamados de agentes.

2) As quantidades são constituídas de espaços quantitativos, que correspondem à descrição dos diferentes estados quantitativos que os objetos podem assumir e, portanto, representam a propriedade dos próprios objetos.

3) Os estados qualitativos, que correspondem às situações qualitativamente distintas em que o sistema pode ser encontrado durante um intervalo determinado de tempo. Constitui uma forma de representação qualitativa das quantidades, portando dois componentes: a magnitude (por exemplo, nulo, pequeno, médio, grande) e a tendência projetada também chamada de derivada (crescente, estável, decrescente).

4) Os processos, que correspondem às relações de dependência, que por sua vez representam as relações de causalidade entre os objetos por meio das influências mútuas sobre suas quantidades.

Segundo a Teoria Qualitativa dos Processos TQP (Forbus, 1984), o comportamento de um sistema é determinado por meio dos processos. Para tanto, esses processos precisam estar modelados de forma explícita (representados) por meio das relações de causalidade.

Nesta teoria, a causa primária das mudanças no sistema é atribuída aos processos, porque estes correspondem a mecanismos que afetam as quantidades dos objetos, cujos efeitos podem ser propagados em outras partes do sistema ao longo do tempo.

$\mathrm{Na} T Q P$, as relações de causalidade são representadas por meio de dois primitivos de modelagem: influências diretas, representadas no modelo por I+e I-, e proporcionalidades qualitativas, representadas por P+e P-.

As influências diretas representam a modelagem dos efeitos diretos dos processos, enquanto as proporcionalidades qualitativas representam a modelagem da propagação dos efeitos dos processos sobre outras quantidades. Essas proporcionalidades qualitativas constituem, portanto, influências diretas. 
Na TQP, é preciso expressar qualitativamente as equações diferenciais, de forma que as restrições são colocadas sobre as derivadas das quantidades, e não nas próprias quantidades. Uma vez que, no âmbito do modelo, a representação da dinâmica deve obedecer à sintaxe adotada no modelo, a influência direta é representada por I+ (Q1, Q2), significando que $\mathrm{dQ} 1 / \mathrm{dt}=\ldots+\mathrm{Q} 2 \ldots$. Da mesma forma, a proporcionalidade qualitativa é representada por $P+(Q 3, Q 4)$, cujo significado matemático que expressa a relação de causalidade indica que Q3 encontra-se ligada a Q4 por meio de uma função monotônica tal que, quando Q4 estiver variando, Q3 também variará na mesma direção, e que é que Q4 causa mudanças em Q3.

Uma das vantagens da modelagem qualitativa sobre outros métodos de modelos de simulação é o fato de o $R Q$ produzir múltiplos resultados a partir de uma mesma simulação. Essa característica é chamada "envisionment" e possibilita o modelador verificar todos os resultados possíveis e inspecionar as contradições entre as relações que levam aos múltiplos caminhos da simulação (Mclntosh 2003).

Segue a definição de alguns termos utilizados na modelagem qualitativa: Fragmentos de modelos, partes de conhecimentos expressados pelo modelo que o GARP3 combina para rodar a simulação. Cenário inicial descreve o estado inicial do sistema que o software usa como condição para acessar os fragmentos de modelo. Entidades são objetos físicos e conceitos que constituem os compartimentos do sistema e Agentes são entidades que afetam, mas não são afetados pelo sistema. Espaços quantitativos são gama de possíveis valores que determinada quantidade pode apresentar (ex: médio, alto, baixo). Os espaços quantitativos são definidos por pontos ou intervalo. Grafo de estado representa uma seqüência de Estados, que são situações em que o sistema pode apresentar. Modelo causal é um diagrama contendo todas as quantidades e as dependências causais (P's e l's). Para cada estado, de determinada simulação, produz-se um Modelo causal. Finalmente, História de valores descreve como determinada quantidade muda durante certo intervalo de tempo.

Para modelagem foi utilizado o software GARP3 1.4.11 (Bredeweg et al., 2009) que simula um comportamento de um sistema através de uma abordagem composicional (Falkenhaier \& Forbus, 1991), tendo como base a teoria qualitativa dos processos (Forbus, 1984).

A validação do modelo foi realizada por meio da apresentação da versão preliminar do modelo durante o I Workshop Internacional "Sustentabilidade Socioambiental da Bacia da Lagoa Mirim", realizado em Pelotas (RS, Brasil), entre os dias 20 e 22 de maio de 2009. No processo de validação, foram acolhidas diversas críticas e contribuições de especialistas presentes no referido evento para fins de revisão final do presente modelo. Este procedimento correspondeu à validação conceitual descrita em Rykiel-Jr (1996), sendo que a validação operacional foi feita durante a construção do modelo e implementação das simulações a partir dos cenários iniciais.

\section{RESULTADOS E DISCUSSÃO}

O modelo final possuiu 8 entidades representadas na Tabela I e as configurações estão representadas na Tabela II. A modelagem representou os

Tabela 1 - Entidades, variáveis e espaços quantitativos utilizados no modelo.

\begin{tabular}{lll}
\hline \hline Entidades & Variáveis & $\begin{array}{l}\text { Espaço } \\
\text { quantitativo }\end{array}$ \\
\hline Lagoa & $\begin{array}{l}\text { Incidência vento } \\
\text { Profundidade }\end{array}$ & Mbbmamamax \\
& Sedimento removido & Bma \\
& Velocidade da água & Zp \\
& Quantidade de pontais baixios e ilhas & Bma \\
& Concentração de nitrogênio & Mbbmamamax \\
Macrófitas & Atividade de navegação & Bma \\
Invertebrados & Riqueza e abundância de espécies & Mbbmamax \\
nativos & Riqueza e abundância de espécies & Mbbmamax \\
Aves aquáticas & Riqueza e abundância de espécies & Mbbmamax \\
Peixes & Riqueza e abundância de espécies & Mbbmamax \\
Mexilhão-dourado & Distribuição espacial & Rma \\
Hidrovia (agente) & Taxa de dragagem & Zp \\
\hline \hline Bma: baixa, média, alta & & \\
Zp: zero, positivo & & \\
Rma: restrita, média, ampla & \\
Mbbmamax: muito baixa, baixa, média, alta, máxima & \\
Mbbmamamax: muito baixa, baixa, média, alta, muito alta, máxima &
\end{tabular}


Tabela 2 - Configuração das relações entre as entidades, e suas propriedades.

\begin{tabular}{|c|c|c|c|c|c|}
\hline Entidade Fonte & Configuração & $\begin{array}{l}\text { Entidade- } \\
\text { alvo }\end{array}$ & $\begin{array}{l}\text { Quantidade } \\
\text { Fonte }\end{array}$ & Influência & $\begin{array}{l}\text { Quantidade } \\
\text { Alvo }\end{array}$ \\
\hline Lagoa & & & $\begin{array}{l}\text { Sedimento } \\
\text { removido }\end{array}$ & P- & $\begin{array}{l}\text { Quantidade de } \\
\text { baixios, } \\
\text { pontais e ilhas }\end{array}$ \\
\hline Lagoa & & & $\begin{array}{l}\text { Quantidade de } \\
\text { baixios, pontais } \\
\text { e ilhas }\end{array}$ & P- & $\begin{array}{l}\text { Velocidade da } \\
\text { água }\end{array}$ \\
\hline Lagoa & & & $\begin{array}{l}\text { Quantidade de } \\
\text { baixios, pontais } \\
\text { e ilhas }\end{array}$ & P- & Profundidade \\
\hline Lagoa & & & Profundidade & $\mathrm{P}+$ & $\begin{array}{l}\text { Atividade de } \\
\text { navegação }\end{array}$ \\
\hline Lagoa & & & $\begin{array}{l}\text { Velocidade da } \\
\text { água }\end{array}$ & P- & $\begin{array}{l}\text { Concentração } \\
\text { de nitrogênio }\end{array}$ \\
\hline Lagoa & & & Profundidade & P- & $\begin{array}{l}\text { Concentração } \\
\text { de nitrogênio }\end{array}$ \\
\hline Lagoa & Contêm & $\begin{array}{l}\text { Mexilhão- } \\
\text { dourado }\end{array}$ & $\begin{array}{l}\text { Sedimento } \\
\text { removido }\end{array}$ & $\mathrm{P}+$ & $\begin{array}{l}\text { Distribuição } \\
\text { espacial }\end{array}$ \\
\hline Lagoa & Contêm & $\begin{array}{l}\text { Mexilhão- } \\
\text { dourado }\end{array}$ & $\begin{array}{l}\text { Atividade de } \\
\text { navegação }\end{array}$ & $\mathrm{P}+$ & $\begin{array}{l}\text { Mexilhão- } \\
\text { dourado }\end{array}$ \\
\hline Lagoa & Contém & $\begin{array}{l}\text { Invertebrados } \\
\text { nativos }\end{array}$ & $\begin{array}{l}\text { Concentração } \\
\text { de nitrogênio }\end{array}$ & $\mathrm{P}+$ & $\begin{array}{l}\text { Riqueza e } \\
\text { abundância de } \\
\text { espécies }\end{array}$ \\
\hline Lagoa & Contém & Macrófitas & $\begin{array}{l}\text { Concentração } \\
\text { de nitrogênio }\end{array}$ & $\mathrm{P}+$ & $\begin{array}{l}\text { Riqueza e } \\
\text { abundância de } \\
\text { espécies }\end{array}$ \\
\hline Macrófitas & Afeta & $\begin{array}{l}\text { Invertebrados } \\
\text { nativos }\end{array}$ & $\begin{array}{l}\text { Riqueza e } \\
\text { abundância de } \\
\text { espécies }\end{array}$ & $\mathrm{P}+$ & $\begin{array}{l}\text { Riqueza e } \\
\text { abundância de } \\
\text { espécies }\end{array}$ \\
\hline Macrófitas & Afeta & $\begin{array}{l}\text { Aves } \\
\text { aquáticas }\end{array}$ & $\begin{array}{l}\text { Riqueza e } \\
\text { abundância de } \\
\text { espécies }\end{array}$ & $\mathrm{P}+$ & $\begin{array}{l}\text { Riqueza e } \\
\text { abundância de } \\
\text { espécies }\end{array}$ \\
\hline $\begin{array}{l}\text { Invertebrados } \\
\text { nativos }\end{array}$ & Afeta & $\begin{array}{l}\text { Aves } \\
\text { aquáticas }\end{array}$ & $\begin{array}{l}\text { Riqueza e } \\
\text { abundância de } \\
\text { espécies }\end{array}$ & $\mathrm{P}+$ & $\begin{array}{l}\text { Riqueza e } \\
\text { abundância de } \\
\text { espécies }\end{array}$ \\
\hline Lagoa & Contém & $\begin{array}{l}\text { Aves } \\
\text { aquáticas }\end{array}$ & $\begin{array}{l}\text { Velocidade de } \\
\text { água }\end{array}$ & P- & $\begin{array}{l}\text { Riqueza e } \\
\text { abundância de } \\
\text { espécies }\end{array}$ \\
\hline Peixes & Afeta & $\begin{array}{l}\text { Aves } \\
\text { aquáticas }\end{array}$ & $\begin{array}{l}\text { Riqueza e } \\
\text { abundância de } \\
\text { espécies }\end{array}$ & $\mathrm{P}+$ & $\begin{array}{l}\text { Riqueza e } \\
\text { abundância de } \\
\text { espécies }\end{array}$ \\
\hline $\begin{array}{l}\text { Invertebrados } \\
\text { nativos }\end{array}$ & Afeta & Peixes & $\begin{array}{l}\text { Riqueza e } \\
\text { abundância de } \\
\text { espécies }\end{array}$ & $\mathrm{P}+$ & $\begin{array}{l}\text { Riqueza e } \\
\text { abundância de } \\
\text { espécies }\end{array}$ \\
\hline Macrófitas & Afeta & Peixes & $\begin{array}{l}\text { Riqueza e } \\
\text { abundância de } \\
\text { espécies }\end{array}$ & $\mathrm{P}+$ & $\begin{array}{l}\text { Riqueza e } \\
\text { abundância de } \\
\text { espécies }\end{array}$ \\
\hline $\begin{array}{l}\text { Mexilhão- } \\
\text { dourado }\end{array}$ & Afeta & Macrófitas & $\begin{array}{l}\text { Distribuição } \\
\text { espacial }\end{array}$ & P- & $\begin{array}{l}\text { Riqueza e } \\
\text { abundância de } \\
\text { espécies }\end{array}$ \\
\hline Lagoa & Contém & Peixes & $\begin{array}{l}\text { Concentração } \\
\text { de nitrogênio }\end{array}$ & $\begin{array}{l}\text { P- (Se Concentração } \\
\text { de nitrogênio for } \\
\text { "muito alta") }\end{array}$ & $\begin{array}{l}\text { Riqueza e } \\
\text { abundância de } \\
\text { espécies }\end{array}$ \\
\hline $\begin{array}{l}\text { Mexilhão- } \\
\text { dourado }\end{array}$ & Afeta & $\begin{array}{l}\text { Invertebrados } \\
\text { nativos }\end{array}$ & $\begin{array}{l}\text { Distribuição } \\
\text { espacial }\end{array}$ & P- & $\begin{array}{l}\text { Riqueza e } \\
\text { abundância de } \\
\text { espécies }\end{array}$ \\
\hline Lagoa & Contém & Macrófitas & $\begin{array}{l}\text { Incidência de } \\
\text { vento }\end{array}$ & P- & $\begin{array}{l}\text { Riqueza e } \\
\text { abundância de } \\
\text { espécies }\end{array}$ \\
\hline Lagoa & Contém & $\begin{array}{l}\text { Aves } \\
\text { aquáticas }\end{array}$ & $\begin{array}{l}\text { Incidência de } \\
\text { vento }\end{array}$ & $\begin{array}{l}\text { P- (Se Vento for } \\
\text { "muito alta") }\end{array}$ & $\begin{array}{l}\text { Riqueza e } \\
\text { abundância de } \\
\text { espécies }\end{array}$ \\
\hline $\begin{array}{l}\text { Mexilhão- } \\
\text { dourado }\end{array}$ & afeta & Peixes & $\begin{array}{l}\text { Distribuição } \\
\text { espacial }\end{array}$ & $\begin{array}{c}\mathrm{P}+\text { (pressuposto } \\
\text { Peixe come } \\
\text { mexilhão) }\end{array}$ & $\begin{array}{l}\text { Riqueza e } \\
\text { abundância de } \\
\text { espécies }\end{array}$ \\
\hline $\begin{array}{l}\text { Hidrovia } \\
\text { (agente) }\end{array}$ & Ocorre & Lagoa & $\begin{array}{l}\text { Taxa de } \\
\text { dragagem }\end{array}$ & |- & $\begin{array}{l}\text { Sedimento } \\
\text { removido }\end{array}$ \\
\hline
\end{tabular}



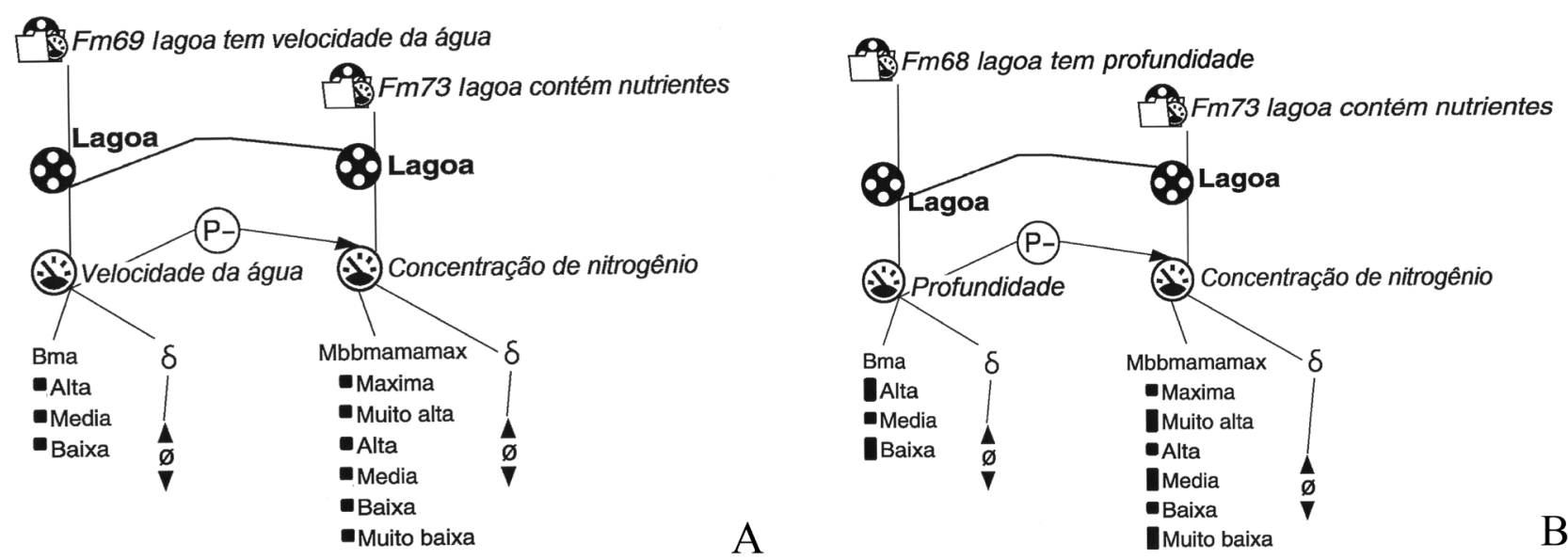

Figura 1 - Influência negativa da (A) velocidade da água e (B) profundidade na quantidade de nutrientes.

parâmetros físico-químicos e biológicos se restringindo a processo que ocorrem dentro da lâmina d'água.

A modelagem procurou explicitar a compreensão dos impactos da atividade de dragagem na lagoa, procedimento considerado imprescindível na implantação da hidrovia. Nesse processo, foi fundamental aprofundar e detalhar a compreensão dos processos ecológicos da Lagoa Mirim, caracterizados pelas interações entre os fenômenos físico-químico-biológicos no interior da mesma.

Uma vez que o $R Q$ baseia-se numa estratégia de modelagem composicional, em que os processos básicos são registrados como fragmentos de modelo reutilizáveis e recombináveis, em vários contextos (Falkenheiner \& Forbus, 1991), cada uma dessas interações físico-químico-biológicas foi modelada como um fragmento de modelo. A versão final do modelo conta com 36 fragmentos de modelos.

A Lagoa Mirim é considerada oligotrófica para o nitrogênio e carbono e eutrófica para o fósforo (Santos et al., 2004). A baixa concentração de nitrogênio é conseqüência da alta diluição desse elemento, uma vez que a lagoa possui grande volume de água, grande espelho d'água, por ser rasa e possuir alta turbulência como conseqüência dos fortes ventos que acometem a região. Apesar disso, estruturas mórficas que se formam na lagoa, como pontais, baixios e ilhas, permitem o aumento da concentração de nutrientes pela diminuição da profundidade e por diminuir a velocidade da água. Os pontais são formações de ilhas de barreira internas e amplas áreas aluviais baixas. Estas ilhas de barreira internas desenvolvem-se sob a forma de estreitos cordões arenosos. Por outro lado o prolongamento dos pontais são formações de bancos arenosos chamados de baixios (Vieira \& Rangel, 1988). Estas interações físico-químicas levam ao "efeito remanso" que são áreas de acúmulo de nitrogênio, baixa profundidade e baixa turbulência (Menegheti, 2010). Tal processo está representado pelos fragmentos de modelos da Figura 1 e o modelo causal na Figura 2.

O efeito remanso possui grande importância para a comunidade biológica da Lagoa Mirim. Primeiramente, o aumento da quantidade de nitrogênio e matéria orgânica permite o estabelecimento de macrófitas e invertebrados nativos. Os invertebrados nativos afetam positivamente a abundância e riqueza de peixes que deles se alimentam (Figura 3). Levantamentos ictiológicos na bacia revelam que

\section{Lagoa}

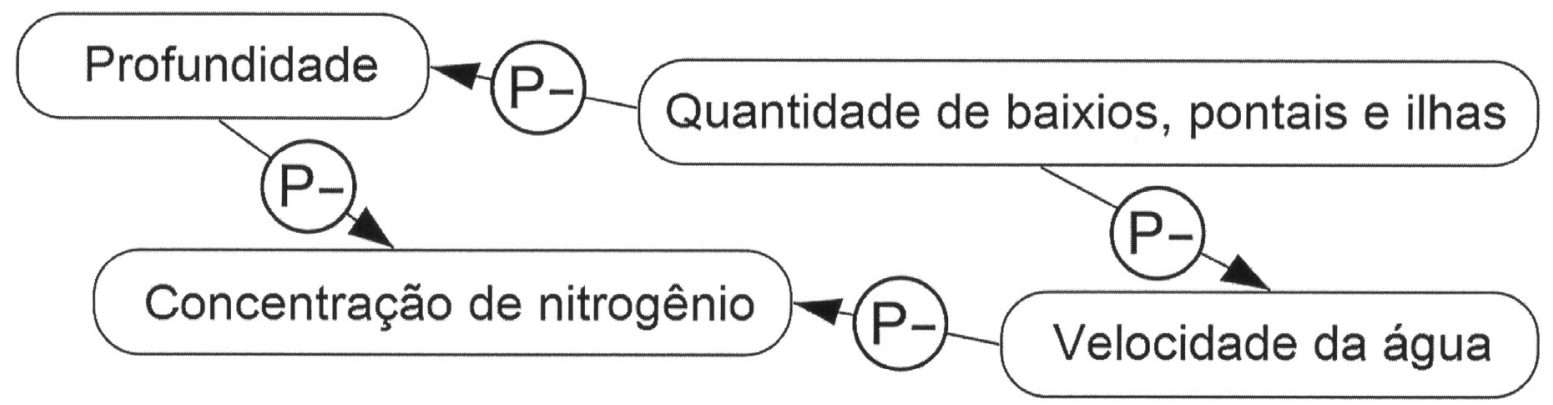

Figura 2 - Modelo causal mostrando o "efeito remanso" nas características físico-químicas da lagoa. O diagrama mostra que Profundidade afeta negativamente Concentração de nitrogênio; Quantidade de baixios, pontais e ilhas afeta negativamente Velocidade da água e Profundidade; Velocidade da água afeta negativamente Concentração de nitrogênio. 


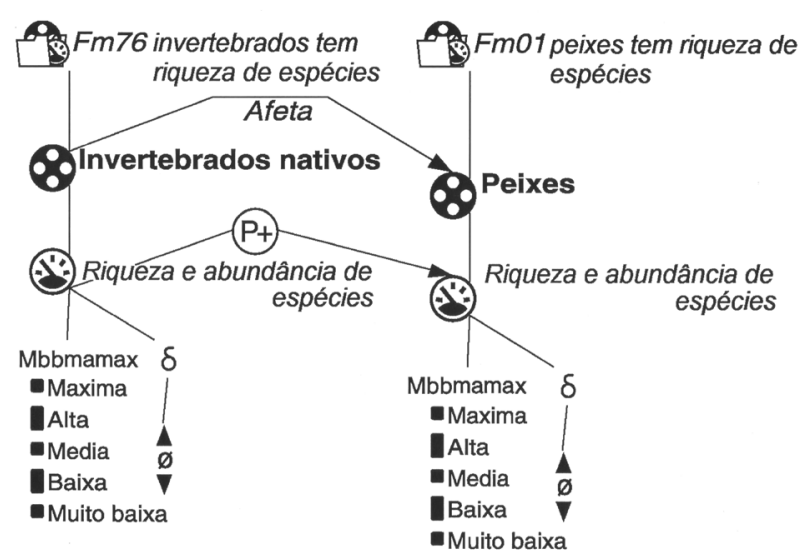

Figura 3 - A riqueza de invertebrados nativos afeta positivamente a riqueza de peixes.

a lagoa é habitada por pelo menos 50 espécies de peixes (Sobrinho, 2009; Burns et al., 2006a; Garcia et al., 2006). A influência dos invertebrados nativos na riqueza de peixes está representada na Figura 3.

Além disso, a riqueza de invertebrados nativos afeta também a riqueza de aves aquáticas. A Lagoa Mirim é habitada por 45 espécies de aves limícolas distribuídas entre as famílias Jacanidae, Rostratulidae, Haematopodidae, Recurvirostridae, Charadriidae e Scolopacidae (Meneguethi, 2009). Ainda segundo este autor, as estruturas mórficas e a presença de macrófitas protegem as aves dos fortes ventos, promovendo sua maior densidade nas áreas de remanso. Este efeito está representado na Figura 4. As aves aquáticas também se beneficiam da riqueza de peixes uma vez que muitas delas são piscívoras.

Este equilíbrio dinâmico que assegura alta biodiversidade encontra-se ameaçado. Além da pressão antrópica direta das atividades econômicas, a Lagoa Mirim também sofre com a pressão exercida pela in-

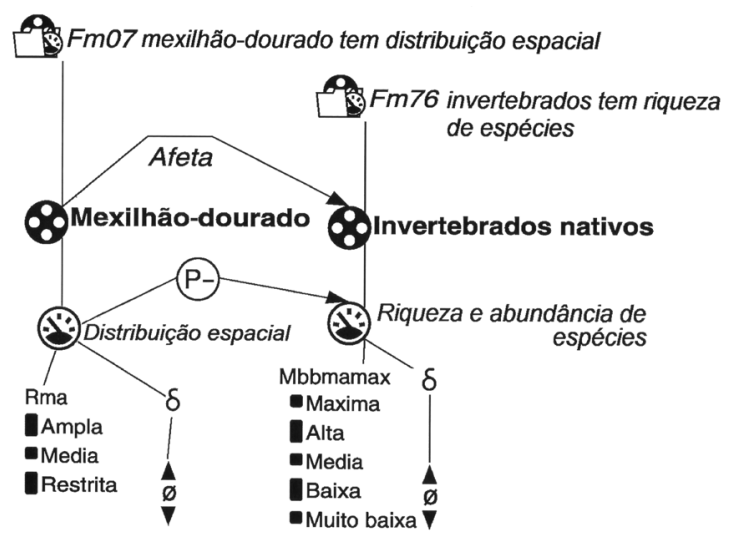

Figura 5 - Influência da distribuição espacial do mexilhão-dourado na riqueza de invertebrados nativos.

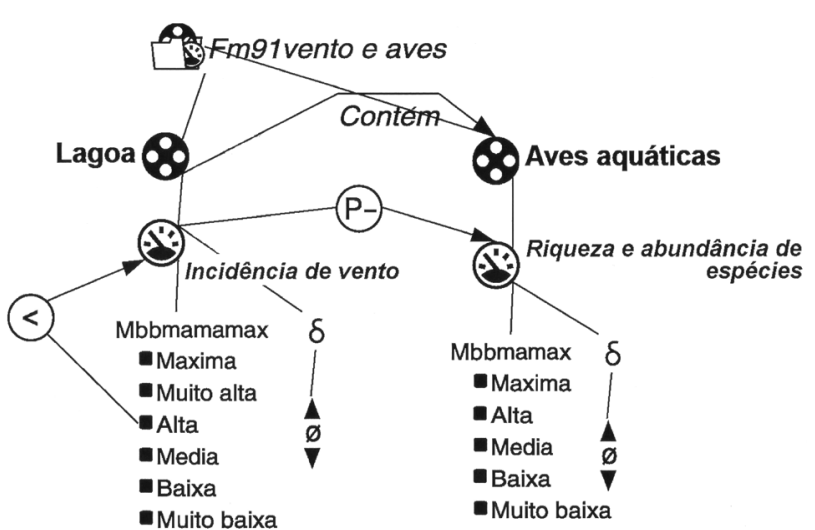

Figura 4 - Fragmento de modelo representando o efeito do vento na riqueza de espécies de aves aquáticas. Lê-se: se a Incidência de Vento for maior do que "Alta", então a Incidência de Vento afeta negativamente a Riqueza e abundância de Aves aquáticas.

trodução de espécies exóticas. O mexilhão-dourado (Limnoperna fortunei: Mollusca) é originário do sudeste asiático e foi registrado pela primeira vez na Lagoa Mirim em 2004 (Burns et al., 2006b). Ele causa prejuízos econômicos e pode levar ao declínio de espécies de invertebrados nativos epibentônicos (Magara et al., 2001; Mansur et al., 2003), sendo que tal efeito está representado na Figura 5. Na lagoa foi registrado um indivíduo de decápoda carregando 20 vezes o seu peso incrustado em sua carapaça (Sobrinho, 2009).

O mexilhão-dourado também pode, em teoria, influenciar positivamente a riqueza da ictiofauna (Sobrinho, 2009) uma vez que muitas espécies podem se alimentar do molusco invasor (Vermulm-Júnior \& Giamas, 2008). No entanto, como se trata de possibilidade remota e cuja influência não apresentaria magnitude suficiente para produzir um aumento real, um aumento nas populações de peixes em função dessa disponibilidade de recurso alimentar foi descartado na modelagem. Tal situação foi lançada na

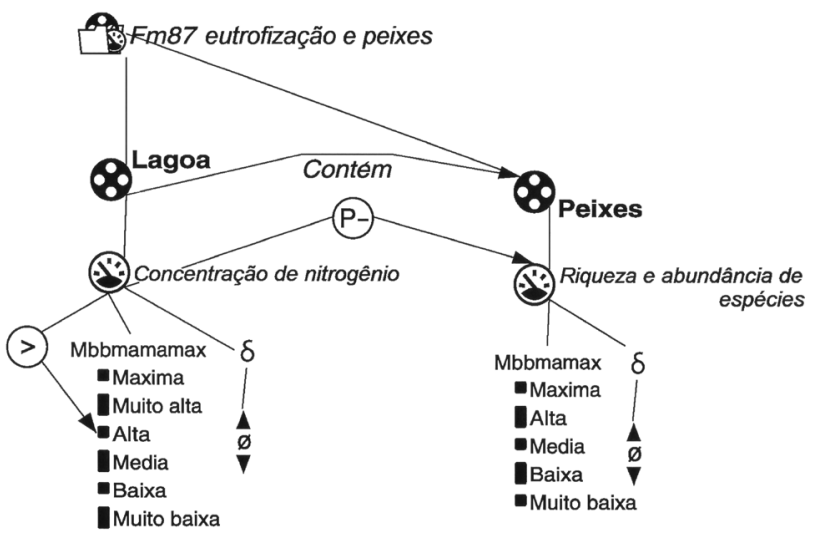

Figura 6 - Fragmento de modelo representando os efeitos negativos da quantidade de nitrogênio na riqueza de espécies peixes. Lê-se: se lagoa contém Peixes e a Concentração de nitrogênio for maior do que "Alta", a Concentração de nitrogênio afeta negativamente a Riqueza e abundância de espécies de Peixes. 


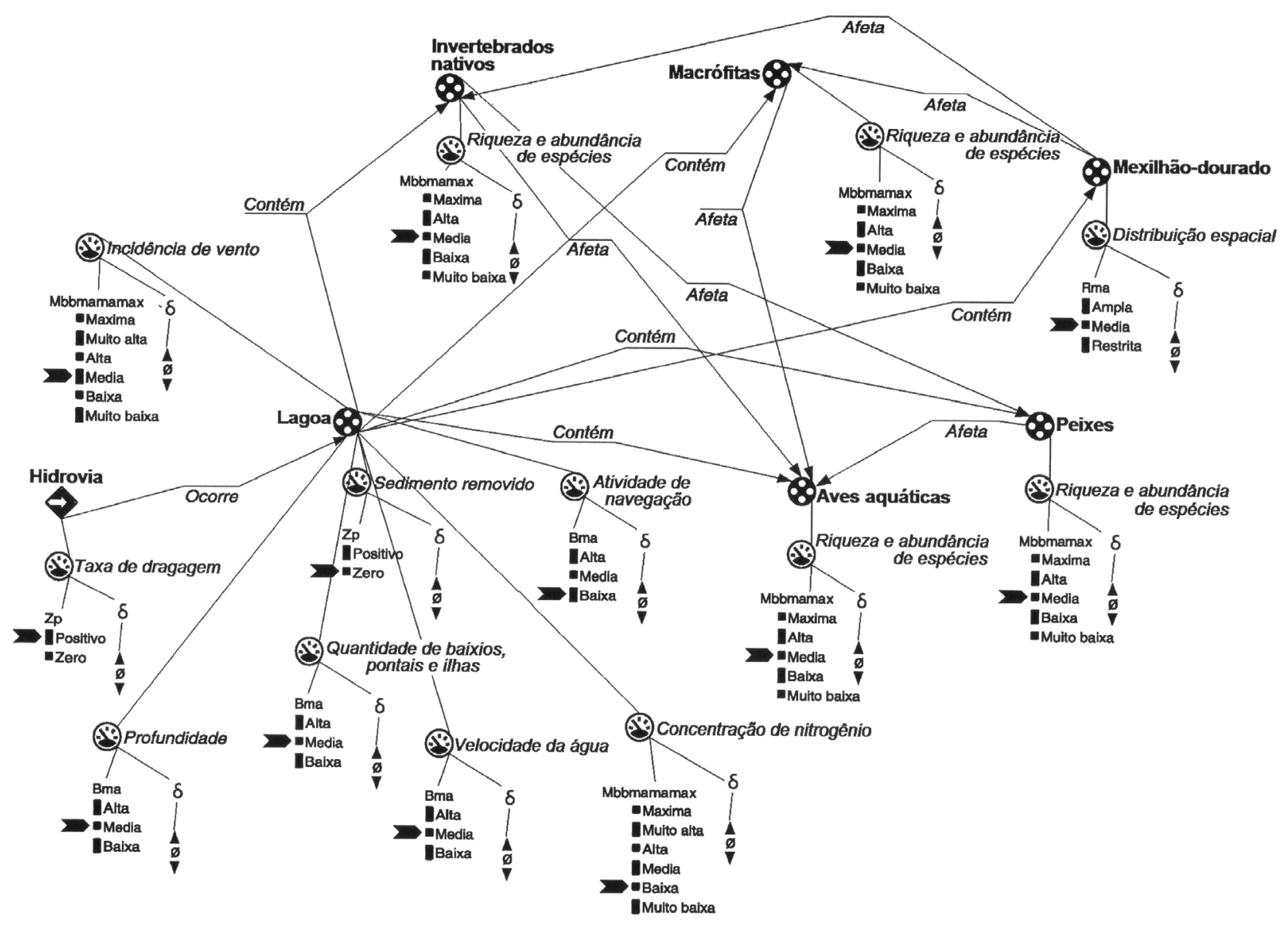

Figura 7 - Cenário inicial da simulação dos impactos da instalação de uma hidrovia nos parâmetros físico-químicos e bióticos alteração realizada. Setas ligando entidades e agente referem-se às configurações e os marcos nas quantidades associadas às entidades referemse aos valores iniciais.

condição de "assumption" (pressuposto) do modelo, permanecendo, para efeitos desse trabalho, inativado (pressuposto não-aceito). A não-aceitação desse pressuposto no modelo pode ser corroborada por uma publicação recente que constatou que $2 / 3$ das espécies de peixes examinados em estudo no reservatório da Usina Hidrelétrica de Itaipu apresentaram presença de moluscos invasores no trato digestivo, sendo que $L$. fortunei se encontrava em maior quantidade que Corbicula fluminea, provavelmente devido à sua maior disponibilidade. No entanto, os autores alertam que o fato da presença de moluscos intactos sugere que os moluscos podem não ser digeríveis e provavelmente passam pelo peixe vivos, e que neste caso, estas espécies de peixes ao invés de controlar a espécie exótica invasora, podem estar contribuindo para disseminá-la (Oliveira et al., 2010). Da mesma forma, como se trata de uma hipótese levantada pelos autores de que a ictiofauna poderia estar contribuindo para disseminação do mexilhão-dourado, tal processo também foi modelado e mantido inativo, ou seja, assumiu-se um pressuposto de neutralidade para fins dessa modelagem. Apesar disso as espécies de macrófitas podem ser impactadas pela presença do mexilhão-dourado, especialmente no caso dos juncos (Silveira et al., 2003; Santos, 2004), uma vez que aqueles se incrustam na base dessas plantas, levando à perda de sua maleabilidade e conseqüentemente a quebra das estruturas com a ação dos ventos. Após a quebra, se completa o processo de incrustação, que impede sua regeneração posterior, levando à diminuição das macrófitas que, por sua vez, protegem as aves da ação de predadores e ventos.

Uma vez que a baixa profundidade é o principal obstáculo à navegação de grande porte, a dragagem levará a remoção do sedimento (representado no modelo pelo aumento do sedimento removido). É esperado que tal processo afete positivamente a distribuição do mexilhão-dourado na lagoa de duas formas: pelo transporte de larvas e adultos que poderiam se incrustar no casco das dragas, e pela infestação nos locais de despejo do sedimento (Sobrinho, 2009).

Outro aspecto representado pelo modelo é a eutrofização, processo pelo qual o aumento excessivo da quantidade de nutrientes leva à mortandade da ictiofauna. Apesar da lagoa ser oligotrófica para o 


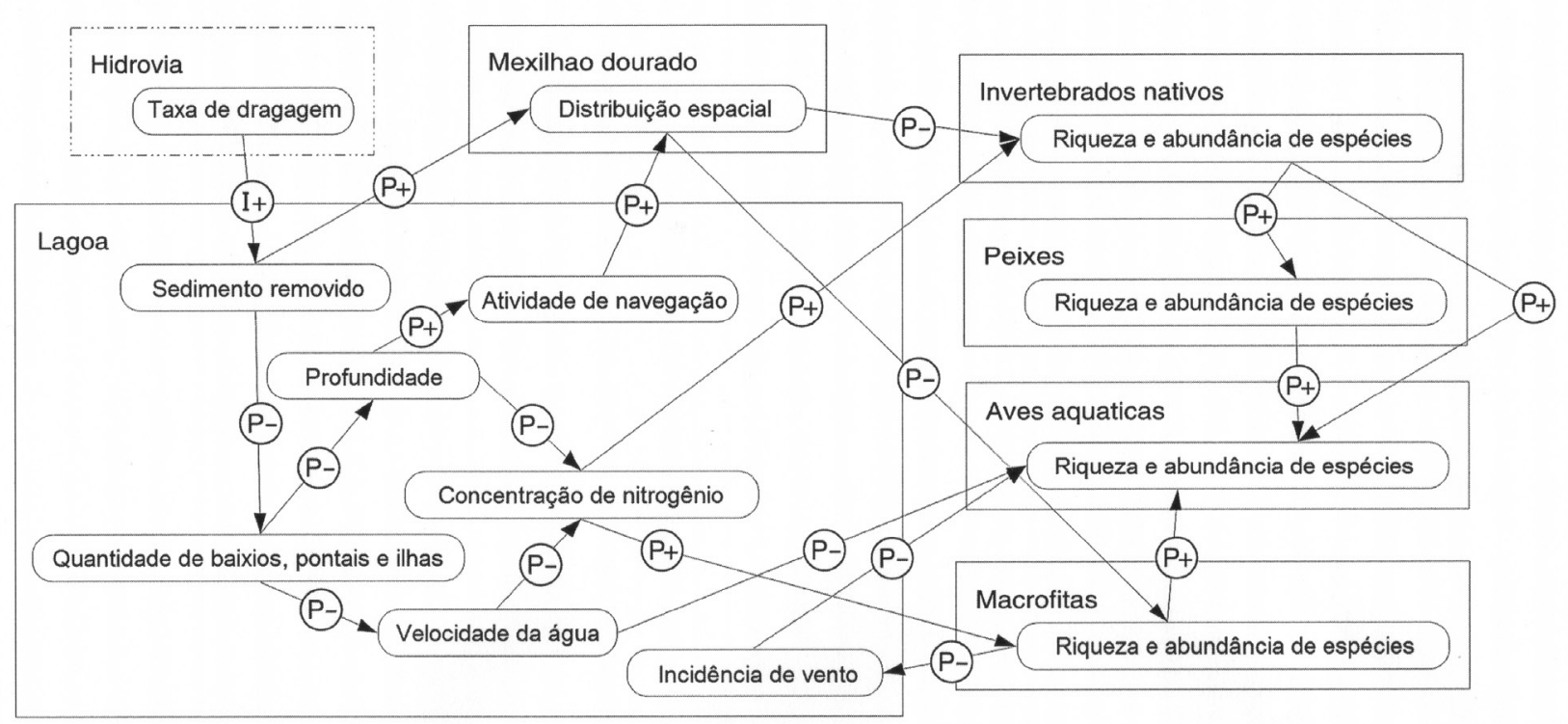

Figura 8 - Modelo causal do último grafo de estado da simulação dos impactos da instalação de uma hidrovia na Lagoa Mirim. Retângulos com linhas contínuas se referem ás entidades (ex. Lagoa, Macrófitas, Peixes, etc...) e o retângulo com linhas trastejadas se refere ao agente (Hidrovia). As quantidades associadas ás entidades e agentes, e a relação entre as mesmas (l+, $\mathrm{P}$ - e P+) também estão representadas.

nitrogênio (Santos et al., 2004), é importante citar esse processo tanto do ponto de vista conceitual, tornando a modelagem mais robusta e real, como do ponto de vista de manejo e conservação. Neste último caso, o aporte excessivo de nutrientes pela expansão urbana ou das atividades agrícolas pode levar a este estado eutrofizado futuramente (ultrapassagem do limiar de estabilidade do sistema) (Figura 6).

A versão final do modelo possui 7 cenários iniciais, sendo o principal deles representado na Figura 7. Um cenário corresponde a uma situação inicial qualquer, a partir do qual o simulador busca os fragmentos de modelo, representando a combinação das entidades, variáveis e configurações da Lagoa Mirim. O efeito remanso está representado pelo valor "zero" para sedimento removido, alta quantidade de pontais, baixios e ilhas, baixa profundidade, quantidade de vento alta, quantidade de nitrogênio média. A atividade de navegação é representada como baixa, uma vez que atualmente existe um tráfego de pequenas embarcações (Menegheti, 2008b). As riquezas de macrófitas, invertebrados nativos, aves aquáticas e peixes são altas, e a distribuição do mexilhão-dourado restrita.

A simulação completa do principal cenário apresentou um estado inicial, um estado final e 193 estados totais.

A Figura 8 é um modelo causal que representa todas as relações de causalidade físico-químicas e biológicas envolvida na construção da hidrovia, com exceção do processo de eutrofização no declínio da ictiofauna, uma vez que este modelo causal se refere a um grafo de estado no qual o valor da quantidade de nitrogênio é menor do que "muito alta". A Figura
8, portanto, exerce aqui o papel do diagrama conceitual, considerado um dos elementos constitutivos fundamentais do entendimento de uma modelagem (Angelini, 2008). O modelo casual lê-se da seguinte forma: taxa de dragagem positiva leva ao aumento do sedimento removido, levando a um declínio da quantidade de pontais, baixios e ilhas. A diminuição das estruturas mórficas leva ao aumento da veloci-

\section{Lagoa: Atividade de navegação}

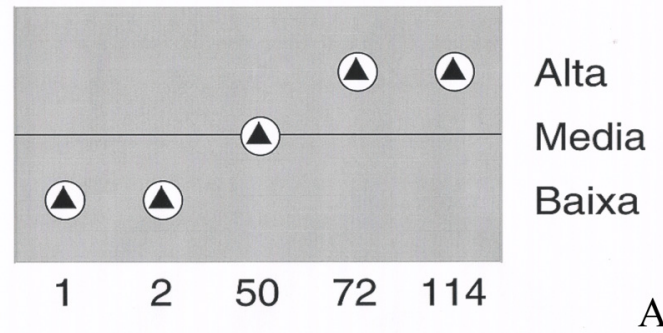

Hidrovia: Taxa de dragagem

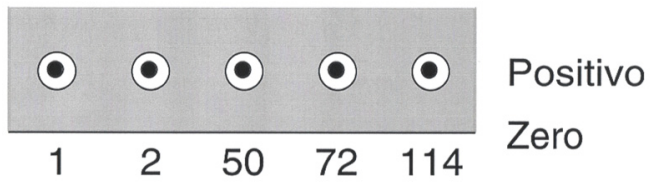

B

Figura 9 - História de valores da (A) atividade de atividade de navegação e (B) taxa de dragagem. Os números abaixo dos diagramas se referem ao número de cada estado produzido a partir da simulação. Como existem ambiguidades, estes não estão ordenados consecutivamente. 
dade da água e ao aumento da profundidade, sendo que estes dois últimos fatores levam à diminuição da quantidade de nitrogênio. Dessa forma, a remoção dos sedimentos pela atividade de dragagem leva à diminuição do efeito remanso. $\mathrm{O}$ aumento da velocidade da água afeta negativamente a riqueza de aves aquáticas e a diminuição da quantidade de nitrogênio afeta negativamente as comunidades de macrófitas e de invertebrados nativos. O declínio da riqueza de macrófitas aumenta a quantidade de vento. A diminuição da riqueza de macrófitas afeta negativamente as aves que delas se alimentam (ex: patos). A diminuição da riqueza de invertebrados nativos também afeta negativamente a avifauna que deles se alimentam (ex: aves limícolas). A perda de espécies de invertebrados nativos afeta negativamente a ictiofauna que também afeta negativamente as aves piscívoras. Com relação à distribuição do mexilhão-dourado, esta é positivamente influenciada pela remoção dos sedimentos e afeta negativamente a riqueza de macrófitas e invertebrados nativos.

Lagoa: Concentração de nitrogênio

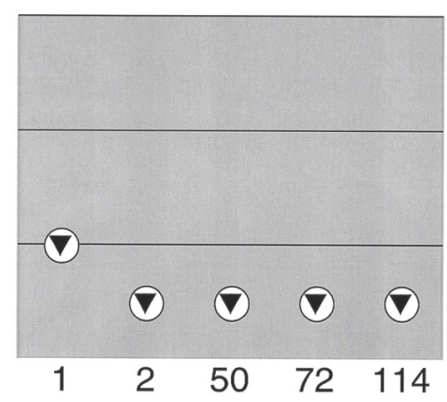

Maxima
Muito alta
Alta
Media
Baixa
Muito baixa
A

Lagoa: Quantidade de baixios, pontais e ilhas
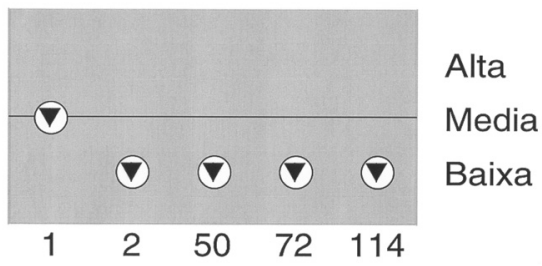

Lagoa: Velocidade da água

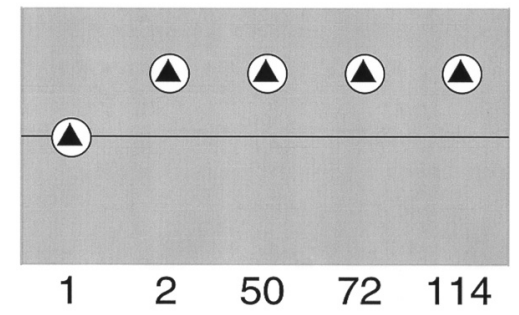

Alta

Media

Baixa

E
As histórias de valores de uma das possíveis trajetórias da simulação estão representada nas Figuras 9, 10 e 11.

A taxa de dragagem da hidrovia é positiva durante toda a trajetória da simulação. A atividade de navegação aumenta de baixa para média (Figura 9).

A quantidade de sedimento removido leva à quebra do "efeito remanso" pela diminuição da quantidade de baixios, pontais e ilhas, aumentando a profundidade. A quantidade de vento passa de alta para muito alta, a velocidade da água sobe de média para alta e a quantidade de nitrogênio diminui de média para baixa (Figura 10).

No que se referem aos parâmetros biológicos da lagoa, a riqueza e abundância das espécies de macrófitas, invertebrados nativos, aves aquáticas e peixes diminuiu de alta para valor médio (Figura 11). A distribuição espacial do mexilhão-dourado aumenta de restrita para média (Figura 12).

A Figura $13(A, B, C, D)$ representa as histórias de valores produzidos pela trajetória alternativa

\section{Lagoa: Profundidade}

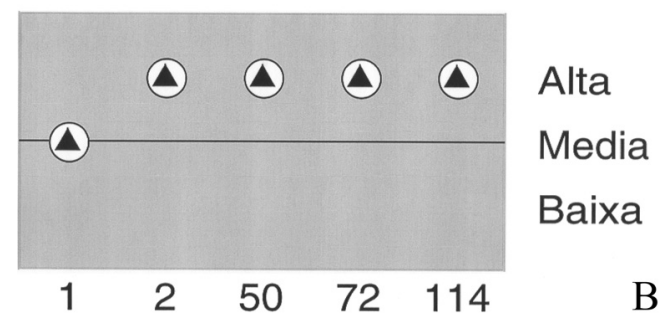

Lagoa: Sedimento removido

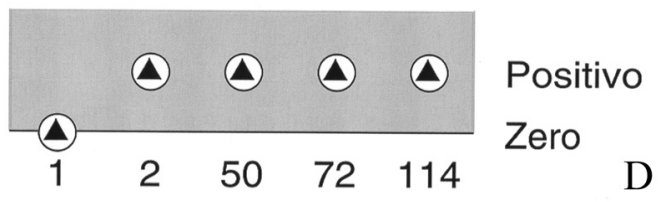

Lagoa: Incidência de vento

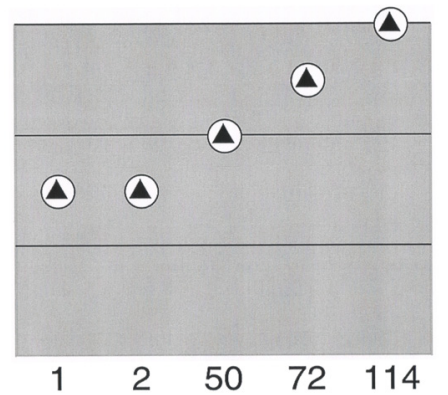

Maxima

Muito alta

Alta

Media

Baixa

Muito baixa

F

Figura 10 - História de valores dos parâmetros físico-químicos da lagoa: (A) Concentração de nitrogênio; (B) Profundidade; (C) Quantidade de pontais, baixios e ilhas; (D) Sedimento removido; (E) Velocidade da água; (F) Incidência de vento. Os números abaixo dos diagramas se referem ao número de cada estado produzido a partir da simulação. Como existem ambiguidades, estes não estão ordenados consecutivamente. 
Aves aquáticas: Riqueza e abundância de espécies

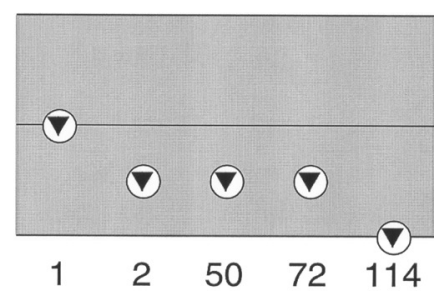

Maxima

Alta

Media

Baixa

Muito baixa

Macrófitas: Riqueza e abundância de espécies

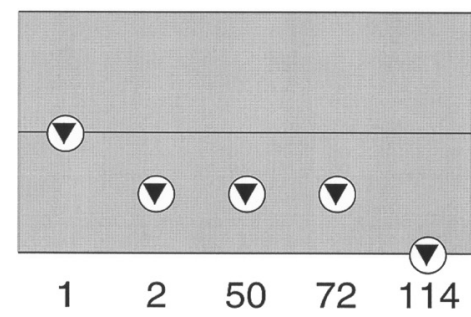

Invertebrados nativos: Riqueza e abundância de espécies

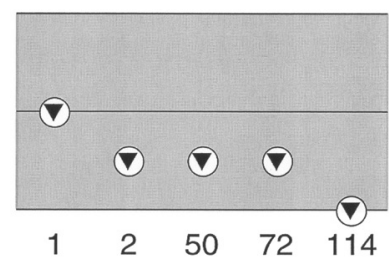

Maxima

Alta

Media

Baixa

Muito baixa

B

Peixes: Riqueza e abundância de espécies

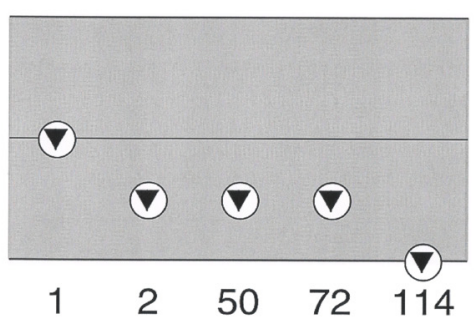

Maxima

Alta

Media

Baixa

Muito baixa

Figura 11 - História de valores da simulação dos parâmetros biológicos da lagoa: Riqueza e abundância de espécies de (A) Aves; (B) Invertebrados nativos; (C) Macrófitas; (D) Peixes. Os números abaixo dos diagramas se referem ao número de cada estado. Como existem ambiguidades, estes não estão ordenados consecutivamente.

da simulação do mesmo cenário inicial. A existência de trajetórias alternativas mostra que existe uma complexidade de interações que podem possibilitar oscilações nos valores em diferentes estados. Essas oscilações indicam que não existe uma única trajetória determinística, mas trajetórias probabilísticas, tal que as tendências ascendentes ou descendentes nos valores sejam conectados pelo simulador de forma a manterem uma sequencia linear e contínua. Apesar dessas diferentes percursos, todas as trajetórias indicam que, em algum momento, a hidrovia provocará prejuízos à biodiversidade da Lagoa Mirim".

A história de valores produzidos nas simulações, a partir do modelo causal de relacionamento entre os fatores (entidades) envolvidos indica que a instalação da hidrovia na Lagoa Mirim levará a uma perda da diversidade biológica e propriedades do ecossistema, mantidas as práticas usuais de draga- gem para remoção do sedimento. Haverá também, nestas condições, impactos na estruturas mórficas da Lagoa, como pontais, baixios e ilhas.

Tal padrão é corroborado pelos estudos que analisaram o impacto, em longo prazo, da instalação de hidrovias de modo geral. Nos EUA, uma hidrovia na região de Everglades levou ao declínio de 95\% das espécies de aves, $80 \%$ da atividade de pesca e perda de $70 \%$ do habitat de invertebrados nativos (Brumbach, 1990).

\section{CONCLUSÃO}

O modelo mostrou claramente que, diante dos conhecimentos disponíveis sobre os processos da lagoa, a instalação da hidrovia levará a uma perda da biodiversidade e ruptura na estabilidade do ecossis-

\section{Mexilhão-dourado: Distribuição espacial}

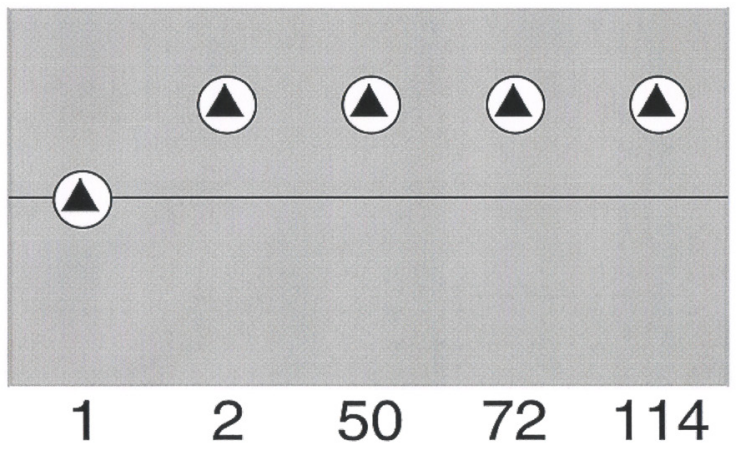

Ampla

Media

Restrita

Figura 12 - História de valores da simulação da distribuição espacial do mexilhão-dourado na lagoa. 
Aves aquáticas: Riqueza e abundância de espécies

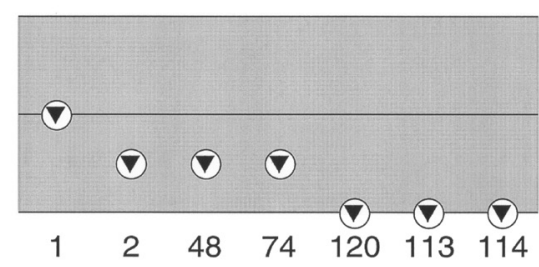

Macrófitas: Riqueza e abundância de espécies

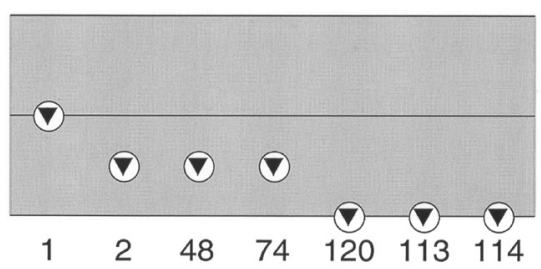

Maxima
Alta
Media
Baixa
Muito baixa

A
Invertebrados nativos: Riqueza e abundância de espécies

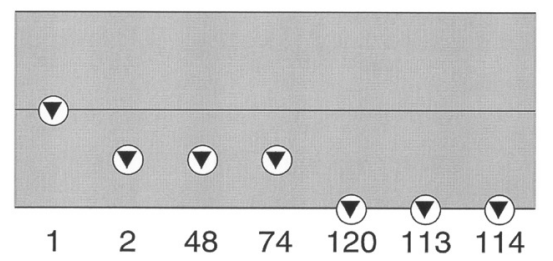

Maxima

Alta

Media

Baixa

Muito baixa

$\mathrm{B}$

Peixes: Riqueza e abundância de espécies

Maxima
Alta
Media
Baixa
Muito baixa $\mathrm{C}$

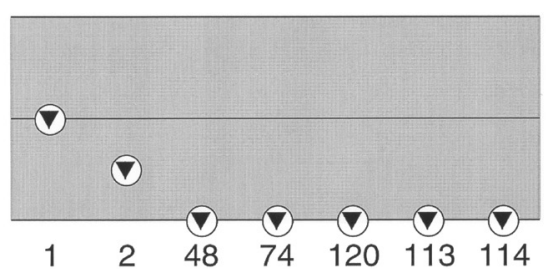

Maxima
Alta
Media
Baixa
Muito baixa

$\mathrm{D}$

Figura 13 - História de valores alternativos da simulação dos parâmetros biológicos da lagoa: Riqueza e abundância de espécies de (A) Aves; (B) Invertebrados nativos; (C) Macrófitas; (D) Peixes. Os números abaixo dos diagramas se referem ao número de cada estado. Como as interações complexas modeladas não são determinísticas, a pluralidade de valores assumidos pelas variáveis nos diferentes estados faz com que o simulador estabeleça trajetórias que passem por caminhos variados, tal que as tendências ascendentes ou descendentes nos valores tenham uma progressão suave, linear e contínua.

tema. O espalhamento do mexilhão-dourado também deverá ocorrer. A simulação mostrou que houve uma diminuição da riqueza de macrófitas, aves aquáticas e invertebrados nativos, além de um aumento da distribuição do mexilhão-dourado. Ademais, o modelo mostrou que pode haver variação no tempo de resposta dependendo de vários fatores como intensidade da dragagem e características locais.

Caso a hidrovia venha a ser concretizada, os resultados dessas simulações devem ser utilizados no intuito de minimizar os danos ambientais, sobretudo quanto à escolha dos sítios de dragagem, procurando preservar os pontais, baixios e ilhas. A presente modelagem sugere também maior atenção quanto aos procedimentos de dragagem, visando evitar a disseminação do mexilhão-dourado, tanto pela incrustação nas dragas, quanto pela deposição dos sedimentos em outros pontos da lagoa, contendo formas larvares do mexilhão-dourado.

Este trabalho procurou mostrar a complexidade do sistema e sua fragilidade frente às intervenções humanas, apontando para a necessidade da discussão sobre a instalação da hidrovia. Neste contexto, é fundamental que nesta discussão se permita a ampla participação de todos os segmentos sociais afetados, positivamente e negativamente, pelo empreendimento. Recomendamos, no entanto, que esta participação deve se realizar com base num arcabouço teórico-científico que permita que cada segmento compreenda a complexidade dos fatores envolvidos e possa decidir sobre a instalação da hidrovia com consciência. Dessa forma, poderá emergir um modelo de desenvolvimento culturalmente aceito, economicamente viável, socialmente justo e ecologicamente correto; enfim sustentável em sua acepção plena.

\section{AGRADECIMENTOS}

Ao Conselho Nacional de Pesquisa Científica e Tecnológica (CNPq), à Agência Brasileira de Cooperação (ABC/Ministério das Relações Exteriores) e, especialmente, aos Professores João Paes Vieira Sobrinho (FURG), João Oldair Menegethi (UFRGS), Valdir Adilson Steinke (UnB) e Paulo Sérgio Bretas de Almeida Salles (UnB), pelas valiosas contribuições na produção deste trabalho. Agradecimentos são devidos também a Mariana Ribeiro Gomes, Rosiane de Araújo Silva, Luzia Etelvina de Almeida, Daniella Lobo Alcebiades Ferreira pelas revisões e comentários nas versões iniciais do modelo.

\section{REFERÊNCIAS BIBLIOGRÁFICAS}

Angelini, R. 2008. A arte da modelagem. In: Angelini, R. \& Gomes, L. C. O artesão de ecossistemas: construindo modelos com dados. Maringá, Ed. UEM, p:13-29.

Angelini, R. \& Gomes, L. C. 2008. Perspectivas para a modelagem de ecossistemas aquáticos no Brasil. In: Angelini, R. \& Gomes, L. C. O artesão de ecossistemas: construindo modelos com dados. Maringá, Ed. UEM, p:169-173.

Araújo, S. C. S.; Salles, P. \& Saito, C. H. 2008. A case study on qualitatitve model evaluation using data 
about river water quality. Ecological Informatics $3(1): 13-25$.

Banducci Jr, A. 2003. Turismo cultural e patrimônio: A memória Pantaneira no curso do Rio Paraguai. Horizontes Antropológicos, Porto Alegre, 9(20): 117-140.

Bredeweg, B.; Linnebank, F.; Bouwer, A. \& Liem, J. 2009. Garp3 - Workbench for qualitative modelling and simulation. Ecological Informatics, 4 (5-6):263-281.

Brumbach, B. C. 1990. Restoring Florida's Everglades: A strategic planning approach. In Berger J, (ed.) Environmental Restoration: Science and Strategies for Restoring the Earth. Washington (DC): Island Press, p.352-361.

Bucher, E.H.; Huszar, P.C. 1995. Critical environmental costs of the Paraguay-Paraná waterway project in South America Ecological Economics 15(1): 3-9.

Burns, M. D. M.; Garcia, A. M.; Vieira, J. P.; Bemvenuti, M. A.; Motta Marques, D. M. L. \& Condini, M. V. 2006a. Evidence of habitat fragmentation affecting fish movement between the Patos and Mirim coastal lagoons in southern Brazil. Neotropical Ichthyology, 4(1):69-72.

Burns, M. D. M.; Geraldi, R. M.; Garcia, A. M.; Bemvenuti, C. E.; Capitoli, R. R. \& Vieira, J. P. 2006b. Primeiro Registro de Ocorrência do Mexilhão Dourado Limnoperna fortunei na Bacia de drenagem aa Lagoa Mirim, RS, Brasil. Biociências, Porto Alegre, 14(1):83-84.

Cardoso, E. R.; Sousa-JR., W. C.; Lopes, E. \& Amend M. R. 2006. Considerações sobre a viabilidade econômica-ambiental da Hidrovia ParaguaiParaná. Megabiodiversidade, 2(1-2): 52-61.

Dêntice, J. A. 2007. Projeto Hidrovia do MERCOSUL. Pelotas: Universidade Federal de Pelotas, 23p.

Falkenhaier, B. \& Forbus, K. 1991. Compositional modeling-finding the right model for the job. Artificial Intelligence Magazine, 51:95-143.

Forbus, K. D. 1984. Qualitative process theory. Artificial Intelligence Magazine (24): 85-168.

Friedman, J. Empowerment: the politics of the alternative development. Cambridge: Blackwell Publishers, 1992.

Garcia, A. M.; Benvenuti, M. A.; Vieira, J. P.; Motta Marques, D. M. L.; Burns, M. D. M.; Moresco, A. \& Condini, M. V. 2006. Checklist comparison and dominance patterns of the fish fauna at Taim Wetland, South Brazil. Neotropical Ichthyology, 4(2): 261-268.

Gonçalves, G. I. 2008. Perspectivas de integração rodo-hidro-ferroviária na exportação de produtos agrícolas e minerais no estado do Mato Grosso do Sul. Dissertação de mestrado, Universidade de São Paulo, Escola de Engenharia de São Carlos, 155p.

Gottgens, J. F.; Perry J. E.; Fortney R. H.; Meyer, J. E.; Benedict, M. \&. Rood, B. E. 2001. The ParaguayParaná Hidrovía: Protecting the Pantanal with Lessons from the Past. Bioscience, 51(4):301-308.

Kotzian, H. B. \& Marques, D. M. 2004. Lagoa Mirim e a convenção Ramsar: um modelo para ação transfronteiriça na conservação de recursos hídricos. Rega 1(2):101-111.

McIntosh, B. S. 2003. Qualitative modelling with imprecise ecological knowledge: framework for simulation. Environ. Model. Softw. 18(4): 295-307

Magara, Y., Matsui, Y., Goto, Y.; Yuasa, A. 2001. Invasion of the non-indigenous nuisance mussel, Limnoperna fortunei, into water supply facilities in Japan. J. Water SRT - Aqua 50: 113-124.

Mansur, M.C.D.; Santos, C.P.; Darrigran, G.; Heydrich, I.; Callil, C.T.; Cardoso, F.R. 2003. Primeiros dados quali-quantitativos do mexilhão-dourado, Limnoperna fortunei (dunker), no Delta do Jacuí, no Lago Guaíba e na Laguna dos Patos, Rio Grande do Sul, Brasil, e alguns aspectos de sua invasão no novo ambiente. Rev. Bras. Zool. 20(1): 75-84.

Menegheti, J. O. 2008a. Necessidade de conservar los sitios de descanso y alimentación en las rutas de migración de aves acuáticas del cono sur de América. BOTIC@ Boletín Trimestral de Información del CERNAR Año 5, Entrega 20 Junio de 2008.

Menegheti, J. O. 2008b. Protagonismo em las Tomas de Decisión como Estratégia Pertinente a la Sustentabilidad de La Cuenca de La Laguna Merín. IX Jornadas de Zoología del Uruguay. Montevideo, Facultad de Ciências, 10/12/2008 a 13/12/2008.

Menegheti, J.O., 2010. A importância de manter estruturas mórficas que originam o efeito "remanso", gerador dos núcleos de biodiversidade da Lagoa Mirim. In: Sustentabilidade socioambiental da bacia da Lagoa Mirim. Filippini Alba, J. M. (Ed. técn.). Pelotas: Embrapa Clima Temperado, p.70-81.

MMA, 2000. Avaliação e Ações Prioritárias para a conservação da biodiversidade da Mata Atlântica e Campos Sulinos/ Instituto Estadual de FlorestasMG. Brasília: Ministério do Meio Ambiente/SBF, 2000. 40p.

Oliveira, C. R. C.; Fugi, R.; Brancalhão, K. P; Agostinho, A. A. 2010. Fish as potential controllers of invasive molluscs in a neotropical reservoir. Natureza \& Conservação 8(2): 140-144. 
Rykiel-Jr, E. J. 1996. Testing ecological models: the meaning of validation. Ecol. Modelling, 90: 229-244.

Saito, C.H. Educação Ambiental no Brasil e a crise socioambiental mundial. Espaço em Revista (Catalão-GO), vol.11, n.2, p. 1-14, 2009. Disponível em http://www.catalao.ufg.br/geografia/iisea/Anais eletrônicos I SEA/files/Conferencistas/Carlos Hiroo Saito.pdf

Saito, C.H.; Steinke, V.A. 2010. Avaliação geoambiental do território brasileiro nas bacias hidrográficas transfronteiriças. Rev. Bras. Gestão Desenvo. Reg., 6(1): 198-230, jan-abr.

Saito, C.H.; Bastos, F.P.; Abegg, I. 2008. Teoriasguia educacionais da produção dos materiais didáticos para a transversalidade curricular do meio ambiente do MMA. Revista Iberoamericana de Educación (Online), v. 45, p. 1-10.

Saito, C.H.; Ruscheinsky, A.; Bastos, F.P.; Nunes, J.B.A.; Silva, L.F.; Carvalho, L.M. 2011. Conflitos Socioambientais, Educação Ambiental e Participação Social na Gestão Ambiental. Sustentabilidade em Debate (Brasília), 2(1): 121138, 2011. Disponível em http://www.red.unb.br/ index.php/sust/article/view/3910/3321

Salles, P.; Bredeweg, B. 1997. Building Qualitative Models in Ecology. In: 11th International Workshop on Qualitative Reasoning (QR'97). Proceedings of the 11th International Workshop on Qualitative Reasoning (QR'97). Instituto di Analisi Numerica C.N.R., Pubblicazioni n. 1036 , Pavia,Italy.

Salles, P., Bredeweg, B., Araújo, S., 2006. Qualitative models about stream ecosystem recover: exploratory studies. Ecol. Modelling 194 (1-3): 80-89.

Santos, C. P. 2004. Avaliação da densidade e crescimento populacional do mexilhão dourado Limnoperna fortunei (Dunker, 1857) em suas diferentes fases de vida no Lago Guaíba, município de Porto Alegre, RS, como subsídios ao controle do bivalve invasor. Dissertação de Mestrado. Universidade Federal do Rio Grande do Sul, Programa de Pós-Graduação em Ecologia, 72p.
Santos, I. R.; Baisch, R.; Lima, G. T. N. P. \& Silva Filho, E. V. 2004. Nutrients in surface sediments of Mirim lagoon, Brazil-Uruguay border. Acta Limnol. Bras. 16(1): 85-94.

Silveira, C. M.; Stumpf, P. P. \& Hartz, S. M. 2003. Predação do mexilhão-dourado Limnoperna fortunei (Dunker, 1857) (Mytilidae) pela piava Leporinus obtusidens Valenciennes, 1846 (Anostomidae) no Lago Guaíba, Porto Alegre, RS. Anais do VI Congresso de Ecologia do Brasil. Fortaleza, p.237-239.

Sobrinho, J. P. V. 2009. O efeito da navegação na dispersão de espécies invasoras na Lagoa Mirim. Palestra proferida no I Workshop Internacional - Sustentabilidade socioambiental da Bacia da Lagoa Mirim. Pelotas-RS, Embrapa Clima Temperado, 20 e 22 de maio de 2009.

Steinke, V. A. 2007. Identificação de áreas úmidas prioritárias para a conservação da biodiversidade na bacia da Lagoa Mirim (Brasil-Uruguai): Subsídios para a gestão transfronteiriça. Tese de Doutorado, Universidade de Brasília, Programa de Pós-Graduação em Ecologia, Brasil, 138 p.

Timonsur, S. A. 2003 Terminal de carga La Charqueada. Montevideo: Timonsur S.A., março 2003. 55p.

Vermulm-Júnior, H. \& Giamas, M. T. D. 2008. Ocorrência do mexilhão dourado Limnoperna fortunei (Dunker, 1857) (Mollusca; Bivalvia; Mytilidae), no trato digestivo do armal Pterodoras granulosus (Valenciennes, 1821) (Siluriformes, Doradidae) do rio Paraná, São Paulo, Brasil. Bol. Inst. Pesca 34(1): 175-179.

Vieira, E. F. \& Rangel, S. R. S. 1988. Planície Costeira do Rio Grande do Sul. Geografia Física, vegetação e dinâmica sócio-demográfica. Ed. Sagra, Porto Alegre, 256p.
Submetido: Abril/2011 Revisado: Novembro/2011 Aceito: Fevereiro/2012 